\title{
How Does Social Interaction Affect Pro-Environmental Behaviors in China? The Mediation Role of Conformity
}

\author{
Yuxin Zhu ${ }^{1}$, Yin Wang ${ }^{2}$ and Ziming Liu ${ }^{3 *}$ \\ ${ }^{1}$ School of Political Science and International Relations, Tongji University, Shanghai, China, ${ }^{2}$ School of International Relations and \\ Public Affairs, Fudan University, Shanghai, China, ${ }^{3}$ School of Social and Public Administration, East China University of Science \\ and Technology, Shanghai, China
}

OPEN ACCESS

Edited by:

Faik Bilgili,

Erciyes University, Turkey

Reviewed by:

Muhammad Umar,

Qingdao University, China

Sevda Kușkaya,

Erciyes University, Turkey

Ferhan Sayin,

Izmir Democracy University, Turkey

*Correspondence:

Ziming Liu

ziming.liu@ecust.edu.cn orcid.org/0000-0002-8867-2682

Specialty section:

This article was submitted to

Environmental Economics

and Management,

a section of the journal

Frontiers in Environmental Science

Received: 02 April 2021

Accepted: 17 May 2021

Published: 01 June 2021

Citation:

Zhu Y, Wang Y and Liu Z (2021) How Does Social Interaction Affect ProEnvironmental Behaviors in China? The

Mediation Role of Conformity.

Front. Environ. Sci. 9:690361.

doi: 10.3389/fenvs.2021.690361
Environmental problems rooted in human behaviors have been the major obstacles to sustainable development in many countries. The promotion of residents' proenvironmental behaviors may serve to mitigate environmental problems. In this paper, we understand residents' pro-environmental behaviors from the perspective of social interaction. We distinguish between low-cost and high-cost pro-environmental behaviors and analyze to what extent social interaction may affect the two types of pro-environmental behaviors and whether conformity plays a mediation role, using the Chinese General Social Survey in 2013. We find that frequent social interaction increases residents' low-cost proenvironmental behaviors but decreases residents' high-cost pro-environmental behaviors. Conformity has no mediation role for low-cost pro-environmental behaviors but has a full mediation role for high-cost pro-environmental behaviors. We conclude that residents have a strong tendency to conform to the behavioral patterns of the social majority when such conformity can save their time, effort, or financial cost. To promote residents' proenvironmental behaviors, their enforcement cost for the residents should be taken into account and adaptive policy instruments should be developed for different types of proenvironmental behaviors.

Keywords: social interaction, pro-environmental behaviors, conformity, mediation effect, environmental problem

\section{INTRODUCTION}

The overexploitation of natural resources has raised many environmental problems, e.g., air pollution, soil degradation, water shortages, waste accumulation, and loss of biodiversity. Such environmental problems may hurt residents' health (Matus et al., 2012; Liu et al., 2020a), reduce labor productivity (Zivin and Neidell, 2012), and threaten the sustainability of economics and society in the long run (Liu and Yu, 2020). Since environmental problems are generally the direct or indirect consequences of various human behaviors (Nordlund et al., 2018; Amoah and Addoah, 2021), the increase of residents' daily pro-environmental behaviors has been believed to be a potential approach to mitigate environmental problems (DeSombre, 2018). Thus, understanding residents' motivation to participate in pro-environmental behaviors seems to be important not only to the literature but also to policy design (Saphores et al., 2012).

Many studies have investigated the importance of internal factors of residents' pro-environmental behaviors, mainly derived from psychological theories, such as the Theory of Planned Behavior or the 
Value-Belief-Norm model (Wang et al., 2014; Xu et al., 2017; Al Mamun et al., 2018). Yet, the role of social interaction in pro-environmental behaviors has been paid limited attention. As an exception, Miller and Buys (2008) found that residents who kept a close connection with others in the community tended to wash their cars in a more environmentally friendly way. Videras et al. (2012) found that social relationship matters for working with others in the community to solve a local environmental problem, volunteering in environmental protection projects, and recycling. Macias and Williams (2014) found that time spent with neighbors can significantly increase residents' pro-environmental lifestyles.

In this paper, we complement the literature by further exploring the role of social interaction in residents' proenvironmental behaviors. Specifically, we investigate whether and to what extent social interaction may affect residents' proenvironmental behaviors. We also investigate how social interaction affects pro-environmental behaviors by testing the mediation role of conformity to the relationship between social interaction and pro-environmental behaviors. The dataset used for analysis in this paper is from the Chinese General Social Survey (CGSS) in 2013.

The contribution of our work to the literature is twofold. First, we distinguish two types of pro-environmental behaviors-the low-cost and high-cost pro-environmental behaviors, and analyze how social interaction may affect different types of pro-environmental behaviors. Since residents' pro-environmental behaviors are cost-sensitive (Arain et al., 2020), the impact of social interaction may vary across different types of pro-environmental behaviors due to changing proportions of surrounding people who engage in a particular type of pro-environment behaviors. Unlike previous studies which often ignore the enforcement cost of pro-environmental behaviors (Meyer, 2015; Schmitt et al., 2018; Wang and Kang, 2018), our paper could be the first empirical work to investigate the relationship between social interaction and pro-environmental behaviors by taking the enforcement cost into account.

Second, in addition to the estimation of the impact of residents' social interaction with other people on proenvironmental behaviors, we also test whether conformity has a mediation effect for such impact using mediation analysis. To the best of our knowledge, there is still limited empirical analysis on how the relationship between social interaction and proenvironmental behaviors occurs. In the paper, we propose that conformity may mediate the effect because recent work has found that people often behave according to their social referents such as family, friends, neighbors, colleagues, organizations or media (Xu et al., 2017), and pro-environmental behaviors can largely be seen as a signal of conformity to their referents (Li et al., 2020a; Vesely et al., 2020). To test the mediation role, we employed a mediation analysis.

The rest of the paper is structured as follows. In section two we briefly review the relevant literature. Data and empirical methods are introduced in section three. In section four, we report the results of the analysis, followed by a discussion and a conclusion in section five and six, respectively.

\section{LITERATURE AND HYPOTHESIS}

Pro-environmental behaviors refer to that individuals consciously taking actions to reduce the negative impact of their behaviors on the environment (Kollmuss and Agyeman, 2002). Depending on the study context, many individual actions have been defined as pro-environmental behaviors, as long as the actions are beneficial to the environment in the particular context (Liu and Feng, 2020). For example, such actions may include water-saving, power-saving, less driving, using shopping bags, recycling, participating in environmental protection activities, and donating to environmental organizations et al. (Wang et al., 2014; Xiao et al., 2018; Zibenberg et al., 2018; Zhang et al., 2020).

Despite the variety, pro-environmental behaviors can be generally classified as different types. Smith-Sebasto and D'Costa (1995) separated them into civic actions, legal actions, financial actions, educational actions, physical actions, and persuasive actions. Stern (2000) categorized them into environmental activism, private-sphere environmentalism, and non-activist behaviors in the public sphere. Hunter et al. (2004) defined individual actions as public and private proenvironmental behaviors. More other studies, however, divided them as low-cost and high-cost pro-environmental behaviors, according to the difficulty in enforcement (Diekmann and Preisendörfer, 2003; Andersson and von Borgstede, 2010; Abrahamse and Steg, 2011). We propose that such separation seems reasonable because it follows the typical assumption of rationality in economics. Indeed, a slight increase in the enforcement of pro-environmental behaviors can reduce residents' participation (Arain et al., 2020).

Residents' pro-environmental behaviors may be structured by various factors. For example, alongside diverse sociodemographic factors which are often controlled in empirical studies, psychological factors such as political, cultural, and altruistic values (van Riper et al., 2019; Ling and Xu, 2020; Liu and Feng, 2020), environmental awareness (Feng and Reisner, 2011; Iosifidi, 2016), internal motivations (Ling and Xu, 2020) and pro-environmental intention (Wang et al., 2014; Al Mamun et al., 2018) are often thought to be important to explain proenvironmental behaviors. A few studies have also explored the importance of external factors, e.g., market or government incentives (Xu et al., 2017; Xiao et al., 2020).

The importance of social interaction has also attracted scientists' attention (Miller and Buys, 2008; Macias and Williams, 2014). The impact of social interaction on proenvironmental behaviors seems to be intuitive. Residents communicating more frequently with their relatives, neighbors or friends allow them to better acknowledge other people's proenvironmental behaviors, which in turn creates group pressure from the community (Macias and Williams, 2014). Huge group pressure may bring out social norms which regulate people's proenvironmental behavior (Farrow et al., 2017). Meanwhile, behaviors against what the majority of people do in the community may raise the physiological cost for the residents due to not fitting in the group (Farrow et al., 2017; Wang and Lin, 2017). Consequently, residents may take conformity behaviors in order to avoid feeling resentment from others in the community 
(Farrow et al., 2017). In other words, conformity will encourage residents who have close social interaction to behave similarly to the people they communicate with (Duarte et al., 2017).

It should be noticed that the relationship between social interaction and pro-environmental behaviors depends critically on what the majority do in the network. If a particular proenvironmental behavior requires residents to sacrifice a small cost, it would be natural to expect that a relatively large proportion of people will carry out it. Residents who have frequent communication with people should then be more likely to perceive group pressure of environmental protection and residents' conformity actions are inclined to be formed into environmental protection behaviors. However, if a particular proenvironmental behavior requires residents to sacrifice relatively large cost, the majority of people may choose not to carry it out (Huang et al., 2020). As a result, residents who have frequent communication with people may perceive that the majority of people are not carrying out it. Residents' conformity actions may then be characterized with less pro-environmental behaviors. According to the above analysis, we propose the following two hypotheses:

$\mathrm{H} 1$ : Social interaction encourages the residents to act similarly towards the actions of the social majority.

$\mathrm{H} 2$ : Conformity plays a mediation role in the relationship between social interaction and pro-environmental behaviors.

\section{DATA AND METHODS}

\section{Data}

In this paper, we use the 2013 Chinese General Social Survey (CGSS) for analysis. The CGSS dataset was collected by the Renmin University of China, which follows a multi-stage stratified probability sampling strategy. The survey aims to collect a nationwide and representative household sample to trace changes in various aspects of society. Specifically, the CGSS (2013) covers a total of 11,439 residents from 480 communities in 28 provinces in mainland China. Structured questions were used in the survey. The information collected in the survey includes the residents' participation in different environmental behaviors, social interaction with relatives or friends, conformity attitude, as well as their sociodemographic information. For this study, we exclude observations with missing values and a total of 10,723 observations were retained.

\section{Empirical Methods}

In order to investigate the impact of social interaction on proenvironmental behaviors and the mediation effect of conformity, we follow the widely used step-by-step approach suggested by Baron and Kenny (1986) and estimate the following models:

$$
\begin{aligned}
P E B & =\alpha_{0}+\alpha_{1} \text { Interaction }+\alpha_{2} X+\varepsilon \\
\text { Conformity } & =\beta_{0}+\beta_{1} \text { Interaction }+\beta_{2} X+\epsilon \\
P E B & =\gamma_{0}+\gamma_{1} \text { Conformity }+\gamma_{2} \text { Interaction }+\gamma_{3} X+\mu
\end{aligned}
$$

where $P E B$ is an index which measures a resident's participation in different types of pro-environmental behaviors. Interaction represents the frequency of the resident's social interaction with other people, such as the resident's friends or relatives. Conformity indicates the resident's tendency to keep consistent with the social attitudes held by the social majority. $X$ is a vector of control variables which may have impacts on a resident's participation in different types of pro-environmental behaviors. $\alpha, \beta$ and $\gamma$ are parameters to be estimated. $\varepsilon, \epsilon$ and $\mu$ are random disturbance terms for the corresponding models.

According to Baron and Kenny (1986), some conditions must hold to establish mediation: First, social interaction must affect proenvironmental behaviors in Eq. 1; Second, social interaction must affect conformity in Eq. 2; Third, conformity must affect proenvironmental behaviors in Eq. 3 and then the effect of social interaction on pro-environmental behaviors must be less in Eq. 3 than that in Eq. 1. While some study believes that a significant $\alpha_{1}$ in Eq. 1 is the precondition to proceed the estimation of Eq. 2 and Eq. 3 (Cerin et al., 2006), other studies argue that even if the $\alpha_{1}$ is statistically insignificant, it does not necessarily imply the absence of mediation effect, because suppressors which produce controversial effects on the outcome variables may exist to neutralize the mediators (Shrout and Bolger, 2002). Nevertheless, if $\beta_{1}$ in Eq. 2 and $\gamma_{1}$ in Eq. 3 are both significant, conformity has a mediation effect on the relationship between social interaction and proenvironmental behaviors; particularly, if $\gamma_{2}$ is insignificant, conformity has a full mediation effect; if $\gamma_{2}$ remains significant as that in Eq.1, conformity has a partial mediation effect (Baron and Kenny, 1986). Figure $\mathbf{1}$ in the appendix provides a general introduction of the step-by-step approach.

However, the step-by-step approach has been known to be with several limitations. First, it does not provide a direct estimate of the size of the indirect effect (Cerin et al., 2006). Second, it has low statistical power, meaning that when the mediation effect is small, the step-by-step approach may incorrectly reject the presence of the mediation effect (MacKinnon et al., 2002). For example, if at least one of $\beta_{1}$ and $\gamma_{1}$ is insignificant, we cannot

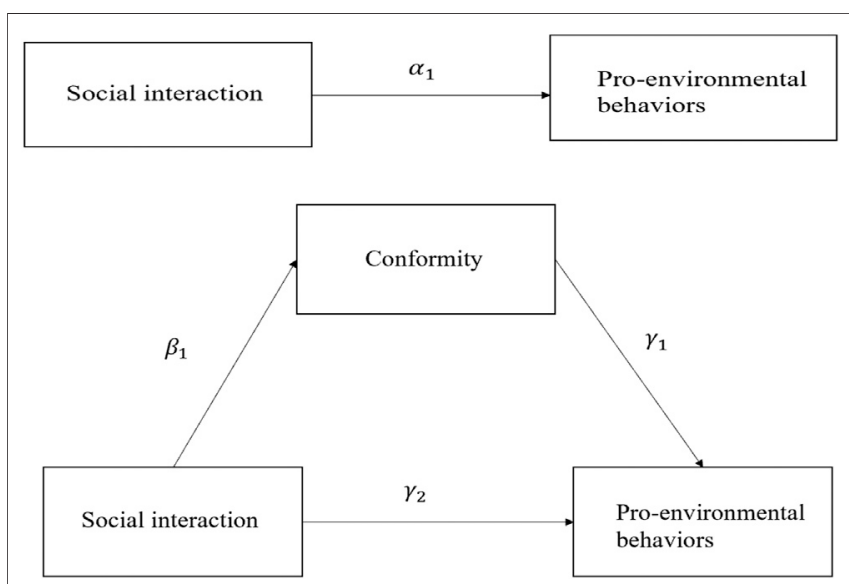

FIGURE 1 | The step-by-step approach. Source: revised according to Baron and Kenny (1986). 
confidentially reject the presence of mediation effect. In fact, the key for testing the presence of a mediation effect is not the significance of $\beta_{1}$ or $\gamma_{1}$, but the joint significance of their product, which is $\beta_{1} * \gamma_{1}$ (Hayes, 2009). Thus, a bootstrap technique which is more promising for the test of mediation effect (Welsch et al., 2021) must be employed to estimate the significance of $\beta_{1} * \gamma_{1}$.

\section{Variable Definitions}

The dependent variable is the residents' performance in proenvironmental behaviors. Following the literature (Andersson and von Borgstede, 2010; Abrahamse and Steg, 2011), we define the low-cost and the high-cost pro-environmental behaviors, respectively, (Table 1). Specifically, low-cost proenvironmental behaviors include sorting waste, discussing environmental problems with others, bringing their own bags in daily shopping, recycling plastic bags, and learning about news on environmental protection from media. These five activities generally cost the residents small effort, time, or money to do. High-cost pro-environmental behaviors include five more costly activities, such as donating for environmental protection, participating in programs on environmental campaign or education, participating in environmental activities organized by environment-protection organizations, conducting forest or green land conservation at one's own expense, and appealing to the government to solve environmental problems.

For each specific pro-environmental behavior, the respondents were asked how often they did it before, with the answers being valued as " $1=$ never", " $2=$ sometimes" and " $3=$ often". Following Andersson and von Borgstede (2010), we sum up the answers for pro-environmental behaviors in each category to generate the indexes to measure the residents' performance in low-cost and high-cost pro-environmental behaviors, respectively. A higher score in the index implies a more frequent participation in the specific category of pro-environmental behaviors.

Similar to Videras et al. (2012), we choose the residents' closeness of contact with friends or relatives to measure their social interaction. Specifically, in the survey the respondents were asked how close their contact with friends or relatives. We assign a value of 1-5 to the residents' answers of "very disclose", "disclose", "normal", "close" and "very close", respectively. The higher value implies more social interaction with friends or relatives. The mediation variable is conformity. In the questionnaire, the residents were asked how often their opinions had been consistent with the popular opinions in the society. In line with Bond (2005) we assigned the answers of "very infrequent", "infrequent", "normal", "frequent" and "very frequent" with values from one to five to measure conformity.

We also include other variables that may affect proenvironmental behaviors. We controlled the residents' age, gender, educational attainment and marital status, because the older, female, more educated and married residents appear to be more likely to participate in pro-environmental behaviors (Liu and Feng, 2020). We also include the residents' working status in the model because employment status is a significant predictor of proenvironmental behaviors (Wang and Kang, 2018). Chinese communist party members are more concerned with environmental problems (Xiao et al., 2013). Thus, we control communist party membership in the model and expect that communists are more likely to participate in pro-environmental behaviors. Family size and structure may be correlated with the amount of consumption and consequently may affect pro-environmental behaviors (Saphores et al., 2012), thus we control family size and the number of children in the family in the model.

We include the residents' urban or rural origin, because residents from urban and rural areas may behave differently (Berenguer et al., 2005). Perceived levels of social classes are included. Residents who believe that they are in higher social classes often take more responsibility for environmental protection (Liu and Feng, 2020). Family asset is controlled because rich families seem to care more about environmental quality (Ponce et al., 2019). Participation in leisure activities which implies more time available may be also related to residents' pro-environmental behaviors. Media use is also controlled because the media (especially the internet) promotes the dissemination of environmental knowledge increasing the possibility of conducting pro-environmental behavior (Gong et al., 2020).

Table 2 shows the definitions and descriptive statistics of the variables in the analysis. In particular, we would like to mention that the mean score of the low-cost pro-environmental behaviors is 9.235 , implying that the average score of each of the five specific low-cost pro-environmental behaviors is close to two, and that most residents choose "sometimes" to participate in a specific low-cost pro-environmental behavior. However, the mean score of the highcost pro-environmental behaviors is much smaller at 5.958, implying that the average score for each of the five specific highcost pro-environmental behaviors is close to one, and that most

TABLE 1 | Two categories of pro-environmental behaviors.

variables

Low-cost pro-environmental behaviors

High-cost pro-environmental behaviors
Specific pro-environmental behavior

The frequency of sorting waste

The frequency of discussing environmental problems with others

The frequency of bringing their own bags in daily shopping

The frequency of recycling plastic bags

The frequency of learning about news on environmental protection from media

The frequency of donating for environmental protection

The frequency of participating in programs on environmental campaign or education

The frequency of participating in environmental activities organized by environment-protection organizations

The frequency of conducting forest or green land conservation at one's own expense

The frequency of appealing to the government to solve environmental problems

Notes: Authors' own design 
TABLE 2 | Variables description.

\begin{tabular}{|c|c|c|c|c|c|c|}
\hline variable name & Variable definition & $\mathbf{N}$ & Min & Max & Mean & S.D. \\
\hline $\begin{array}{l}\text { Low-cost pro-environmental } \\
\text { behaviors }\end{array}$ & The summed scores of five pro-environmental behaviors & 10,798 & 5 & 15 & 9.235 & 2.357 \\
\hline $\begin{array}{l}\text { High-cost pro-environmental } \\
\text { behaviors }\end{array}$ & The summed scores of five pro-environmental behaviors & 10,798 & 5 & 15 & 5.958 & 1.624 \\
\hline Social interaction & $\begin{array}{l}\text { Residents' closeness of contact with friends or relatives }(1=\text { very disclose, } 2 \text { = Disclose, } 3= \\
\text { Normal, } 4 \text { = Close, } 5 \text { = Very close) }\end{array}$ & 10,798 & 1 & 5 & 3.437 & 0.847 \\
\hline Conformity & $\begin{array}{l}\text { The frequency of being consistent with popular belief }(1=\text { Very infrequent, } 2=\text { Infrequent, } 3= \\
\text { Normal, } 4=\text { Frequent, } 5 \text { = very frequent })\end{array}$ & 10,798 & 1 & 5 & 3.463 & 0.767 \\
\hline Age & Age of the resident (years) & 10,798 & 17 & 97 & 48.441 & 16.332 \\
\hline Education & $\begin{array}{l}1 \text { = No education, } 2 \text { = Primary school education, } 3 \text { = Junior high school education, } 4= \\
\text { Senior high school and technical secondary school education, } 5 \text { = College, undergraduate, } \\
\text { graduate, and above }\end{array}$ & 10,723 & 1 & 5 & 3.027 & 1.270 \\
\hline Male & $1=$ Male, $0=$ Female & 10,798 & 0 & 1 & 0.505 & 0.500 \\
\hline Married & $1=$ Married, $0=$ Unmarried & 10,798 & 0 & 1 & 0.787 & 0.410 \\
\hline Having a job & $1=$ Working, $0=$ Not working & 10,798 & 0 & 1 & 0.628 & 0.483 \\
\hline Communist & 1 = Communist Party member, 0 = Otherwise & 10,798 & 0 & 1 & 0.102 & 0.303 \\
\hline Family size & The number of family members & 10,798 & 1 & 12 & 3.095 & 1.413 \\
\hline Number of children & The number of children & 10,798 & 0 & 10 & 1.686 & 1.271 \\
\hline Rural & $1=$ Located in rural area, $0=$ Located in urban area & 10,798 & 0 & 1 & 0.552 & 0.497 \\
\hline Family asset & The number of houses the family own & 10,798 & 0 & 10 & 1.100 & 0.536 \\
\hline Level of social class & Assign a value of $1-10$ from low to high & 10,798 & 1 & 10 & 4.326 & 1.673 \\
\hline Leisure time & The summed scores of eleven leisure activities & 10,798 & 11 & 54 & 24.116 & 5.842 \\
\hline Media use & $\begin{array}{l}\text { The frequency of surfing the Internet }(1=\text { Never, } 2=\text { Seldom, } 3=\text { Sometimes, } 4=\text { Often, } 5= \\
\text { Frequently) }\end{array}$ & 10,798 & 1 & 5 & 2.210 & 1.557 \\
\hline
\end{tabular}

Note: This table was created by the authors.

TABLE 3 | The impacts of social interaction on pro-environmental behaviors using OLS.

\begin{tabular}{|c|c|c|c|c|}
\hline \multirow[t]{2}{*}{ Variables } & \multicolumn{2}{|c|}{ Low-cost pro-environmental behaviors } & \multicolumn{2}{|c|}{ High-cost pro-environmental behaviors } \\
\hline & Coeff & S.D. & Coeff & S.D. \\
\hline Social interaction & $0.135^{\star \star \star}$ & 0.024 & $-0.034^{*}$ & 0.018 \\
\hline Age & $0.013^{\star \star \star}$ & 0.002 & $0.004^{\star \star \star}$ & 0.001 \\
\hline Education & $0.306^{\star \star \star}$ & 0.025 & $0.118^{\star \star \star}$ & 0.018 \\
\hline Male & $-0.318^{\star \star \star}$ & 0.042 & $0.082^{\star \star \star}$ & 0.030 \\
\hline Married & $0.237^{\star \star \star}$ & 0.052 & $-0.084^{\star \star}$ & 0.038 \\
\hline Having a job & 0.018 & 0.046 & $0.179^{\star \star \star}$ & 0.033 \\
\hline Communist & $0.179^{\star \star}$ & 0.071 & $0.204^{\star \star \star}$ & 0.051 \\
\hline Family size & -0.007 & 0.015 & 0.010 & 0.011 \\
\hline Number of children & $-0.101^{\star \star \star}$ & 0.022 & $-0.030^{\star}$ & 0.016 \\
\hline Rural & $-0.696^{\star \star \star}$ & 0.051 & $-0.070^{\star}$ & 0.037 \\
\hline Family asset & -0.015 & 0.038 & -0.007 & 0.028 \\
\hline Level of social class & 0.016 & 0.012 & $0.037^{\star \star \star}$ & 0.009 \\
\hline Leisure time & $0.098^{\star \star \star}$ & 0.004 & $0.078^{\star \star \star *}$ & 0.003 \\
\hline Media use & $0.062^{\star \star \star}$ & 0.019 & $0.028^{\star \star}$ & 0.014 \\
\hline Constant & $5.184^{\star \star \star}$ & 0.204 & $3.367^{\star \star \star}$ & 0.148 \\
\hline Observations & 10,723 & - & 10,723 & - \\
\hline Adjusted $R^{2}$ & 0.236 & - & 0.150 & - \\
\hline
\end{tabular}

Notes: Authors' own computation. * ${ }^{* *}$ and ${ }^{* * *}$ indicate a significant level of 10, 5 and 1\%, respectively.

residents choose "never" to participate in a specific high-cost proenvironmental behavior. These statistics imply that residents who interact more frequently with other people are more likely to acknowledge that the majority of people participate in low-cost pro-environmental behaviors and only a small proportion of people participate in high-cost pro-environmental behaviors. Such different perceived social norms from social interaction then may lead the residents' pro-environmental behaviors to different directions.

\section{RESULTS}

\section{The Impact of Social Interaction on Pro-Environmental Behaviors}

Table 3 reports the impacts of social interaction on low-cost and high-cost pro-environmental behaviors from ordinary least squares regression. The values of adjusted $R^{2}$ for the model of low-cost and high-cost pro-environmental behaviors are 0.236 and 0.150 , respectively. That is to say, the models predict 
$23.6 \%$ of the variance of low-cost pro-environmental behaviors and $15 \%$ of the variance of high-cost pro-environmental behaviors. We find that social interaction has a positive impact on low-cost pro-environmental behaviors. The coefficient is 0.135 with a statistical significance level of $1 \%$. This result suggests that if residents communicate more frequently with their relatives or friends, they are more likely to participate in low-cost pro-environmental behaviors. On the contrary, we find that social interaction has a negative impact on high-cost pro-environmental behaviors. Although the coefficient is relatively small $(-0.034)$, it is statistically significant at $10 \%$. This result suggests that keeping close contact with relatives or friends tends to reduce the residents' probability to participate in high-cost pro-environmental behaviors.

We also find that the older, the more educated and communist party members take more actions for environmental protection. Women are more likely to engage in low-cost pro-environmental behaviors while men are more likely to engage in high-cost proenvironmental behaviors. This is intuitive because low-cost proenvironmental behaviors are related to home activities which are often the responsibilities of women in China while high-cost proenvironmental behaviors are related to actions where men have more decision power. Married residents are more likely to participate in low-cost pro-environmental behaviors but are less likely to participate in high-cost pro-environmental behaviors.

Having a job is important to high-cost pro-environmental behaviors. More children in the family reduce resident's proenvironmental behaviors, probably because residents have to devote more time to the children and have less time for environmental protection. Rural residents have a lower tendency to participate in pro-environmental behaviors than urban residents, probably because urban residents are better informed and more concerned about environmental problems. The higher level of social classes increases residents' high-cost pro-environmental behaviors. More leisure time and media use increase residents' pro-environmental behaviors.

One concern for the above results is that the coefficient of social interaction in OLS regression could be biased due to the presence of endogeneity. For example, residents' social interaction and participation in different types of proenvironmental behaviors may be driven by some omitted variables, e.g., resources to conduct them. In addition, the more environmental actions the resident takes, the more frequently he or she communicates with relatives or friends, which may cause the concern of reverse causality. Furthermore, the variable of social interaction is subjective and based on the respondents' best guess which may cause measurement errors. Any problems of omitted variables, reverse causality or measurement errors can result in endogeneity, i.e., social interaction is correlated with the error terms, and cause biased coefficients in Eq. 1 (Liu and Yu, 2020). Therefore, we employ a two-stage least squares (2SLS) approach to further test the impact of residents' social interaction on proenvironmental behaviors. Compared to the OLS regression, the 2SLS has the advantage of correcting the bias of endogeneity and produces consistent estimates of the coefficients, as long as a valid instrumental variable is available.

In this study we use the mean value of social interaction owned by the rest surveyed samples from the same community as the instrumental variable for social interaction owned by a resident. We argue that the degree of other people's social interaction should have impacts on a resident's social interaction, because a resident's friends or relatives may live in the same community. Besides, a resident may contact more frequently with his/her relatives or friends if he/she observes other residents do so due to peer effects (Frey and Meier, 2004). Yet, the degree of social interaction owned by other residents in the same community should not pose impacts directly on the resident's pro-environmental behaviors. The mean value of other surveyed samples' behavior from the same community has been widely used as an instrumental variable to address the concern of endogeneity in empirical studies (Liu et al., 2017; Liu et al., 2020b).

Table 4 reports the results of the 2 SLS approach. The values of adjusted $R^{2}$ for the model of low-cost and high-cost proenvironmental behaviors are 0.190 and 0.052 , respectively. That is to say, the models predict $19 \%$ of the variance of low-cost pro-environmental behaviors and $5.2 \%$ of the variance of high-cost pro-environmental behaviors. The results show that the $F$-statistic from the test on the strength of the selected instrument variable in the first stage of the 2SLS is 84.16 , which is greater than the critical value of 10. This indicates the selected instrumental variable is strong and there is no concern for a weak instrumental variable. After taking into account the concern of endogeneity, Table 4 shows that social interaction still has a significantly positive impact on low-cost pro-environmental behaviors and a significantly negative impact on high-cost pro-environmental behaviors. Specifically, for the low-cost pro-environmental behaviors the effect of social interaction turns from 0.135 to 0.753 , while for the high-cost pro-environmental behaviors the effect of social interaction turns from -0.034 to -0.652 . Such differences in the results between 2SLS and OLS imply the necessity of addressing endogeneity in the OLS models. However, despite that the absolute values of the coefficients of social interaction from 2SLS are larger than those from OLS, they are generally consistent with each other regarding the directions of impacts.

\section{The Mediation Effect of Conformity}

In the previous section, we have assumed that social interaction affects pro-environmental behavior via residents' conformity. In this section, we formally test this hypothesis using mediation analysis. Specifically, we first report the results from the step-by-step approach and then further present the results from the bootstrap method for a comparison purpose. Table 5 reports the results from Eq. 2 and Eq. 3 estimated from OLS. The values of adjusted $R^{2}$ for the model of conformity, low-cost and high-cost pro-environmental behaviors are 0.027 , 0.236 , and 0.152 , respectively. That is to say, the models predict $2.7 \%$ of the variance of conformity, $23.6 \%$ of the variance of low-cost pro-environmental behaviors and $15.2 \%$ of the 
TABLE 4 | The impacts of social interaction on pro-environmental behaviors using 2SLS.

\begin{tabular}{|c|c|c|c|c|}
\hline \multirow[t]{2}{*}{ variables } & \multicolumn{2}{|c|}{ Low-cost pro-environmental behaviors } & \multicolumn{2}{|c|}{ High-cost pro-environmental behaviors } \\
\hline & Coeff & S.D. & Coeff & S.D. \\
\hline Social interaction & $0.753^{\star \star \star}$ & 0.146 & $-0.652^{\star \star \star}$ & 0.120 \\
\hline Age & $0.015^{\star \star \star}$ & 0.002 & 0.002 & 0.002 \\
\hline Education & $0.286^{\star \star \star}$ & 0.026 & $0.138^{\star \star \star}$ & 0.020 \\
\hline Male & $-0.270^{\star \star \star}$ & 0.045 & 0.034 & 0.033 \\
\hline Married & $0.209^{\star \star \star}$ & 0.054 & -0.056 & 0.040 \\
\hline Having a job & 0.001 & 0.047 & $0.196^{\star \star \star}$ & 0.035 \\
\hline Communist & 0.109 & 0.077 & $0.274^{\star \star \star}$ & 0.063 \\
\hline Family size & -0.019 & 0.016 & $0.022^{*}$ & 0.011 \\
\hline Number of children & $-0.120^{\star \star \star}$ & 0.023 & -0.012 & 0.015 \\
\hline Rural & $-0.762^{\star \star \star}$ & 0.055 & -0.004 & 0.041 \\
\hline Family asset & -0.063 & 0.041 & 0.041 & 0.031 \\
\hline Level of social class & -0.008 & 0.014 & $0.061^{\star \star \star}$ & 0.011 \\
\hline Leisure time & $0.082^{\star \star \star}$ & 0.006 & $0.094^{\star \star \star}$ & 0.005 \\
\hline Media use & $0.060^{\star \star \star}$ & 0.020 & $0.030^{*}$ & 0.016 \\
\hline Constant & $3.681^{\star \star \star}$ & 0.410 & $4.869^{\star \star \star}$ & 0.330 \\
\hline Observations & 10,723 & - & 10,723 & - \\
\hline Adjusted $R^{2}$ & 0.190 & - & 0.052 & - \\
\hline
\end{tabular}

Notes: Authors' own computation. The F-statistic from the test on the strength of instrumental variable in the first stage of the $2 S L S$ is 84.16 ( $\mathrm{p}$-value $=0.000$ ), which is larger than the critical value of ten. ${ }^{*}$ and ${ }^{* * *}$ indicate a significant level of 10 and $1 \%$, respectively.

TABLE 5 | The mediation effects of conformity.

\begin{tabular}{|c|c|c|c|c|c|c|}
\hline \multirow[t]{2}{*}{ variables } & \multicolumn{2}{|c|}{ Conformity } & \multicolumn{2}{|c|}{$\begin{array}{l}\text { Low-cost pro-environmental } \\
\text { behaviors }\end{array}$} & \multicolumn{2}{|c|}{$\begin{array}{l}\text { High-cost pro-environmental } \\
\text { behaviors }\end{array}$} \\
\hline & Coeff & S.D. & Coeff & S.D. & Coeff & S.D. \\
\hline Social interaction & $0.126^{\star \star \star}$ & 0.009 & $0.131^{\star \star \star}$ & 0.025 & -0.019 & 0.018 \\
\hline Conformity & - & - & 0.032 & 0.026 & $-0.114^{\star \star \star}$ & 0.019 \\
\hline Constant & $2.764^{\star \star \star}$ & 0.075 & $5.096^{\star \star \star}$ & 0.217 & $3.683^{\star \star \star}$ & 0.157 \\
\hline Observations & 10,723 & - & - & - & - & - \\
\hline Adjusted $R^{2}$ & 0.027 & 0.236 & 0.152 & - & - & - \\
\hline
\end{tabular}

Notes: Authors' own computation. ${ }^{* *}$ ndicates a significant level of $1 \%$.

variance of high-cost pro-environmental behaviors. We find that social interaction has a positive impact on conformity. The coefficient is 0.126 with a statistical significance level of $1 \%$, suggesting that more frequent communication with relatives or friends tends to make the residents more likely to hold similar attitudes towards the majority of the society. This is in line with previous findings that social interaction with relatives or friends is the fundamental element for the sustainability of social norms (Ostrom, 2000; Nyborg, 2018).

We also find that the impact of conformity is positive on lowcost pro-environmental behaviors. However, the coefficient is relatively small (0.032) and statistically insignificant. In addition, the impact of social interaction on low-cost pro-environmental behaviors remains positive. The coefficient is 0.131 with a statistical significance of $1 \%$. These results seem to imply that conformity has no mediation effect on the relationship between social interaction and low-cost pro-environmental behaviors. However, we have pointed out that the presence of the mediation effect cannot be rejected even if there is an insignificant coefficient when the stepby-step approach was employed. Thus, later we further test the results using the bootstrap method.
For the high-cost pro-environmental behaviors, conformity shows a negative impact. The coefficient is -0.114 with a statistical significance of $1 \%$, implying that residents' conformity attitude reduces their likelihood of participation in high-cost pro-environmental behaviors. After the inclusion of conformity, the impact of social interaction on high-cost proenvironmental behaviors remains negative. However, compared to the estimate in Table 3 , the absolute value of social interaction's coefficient becomes smaller and insignificant. These results seem to imply that conformity has a full mediation effect on the relationship between social interaction and high-cost pro-environmental behaviors.

Given the mentioned drawbacks of the step-by-step approach in the previous section, we further test the robustness of the mediation effect of conformity. Specifically, we use the bootstrap method to draw 1,000 times through repeated random sampling and set a $95 \%$ level of confidence interval. If the lower and upper limits of the $95 \%$ confidence interval for the mediation effect are simultaneously positive (negative), a positive (negative) mediation effect exists. However, if the lower limit is negative and the upper limit is positive, the presence of the mediation 
TABLE 6 | Robustness tests using the bootstrap method.

\begin{tabular}{|c|c|c|c|c|c|c|c|c|}
\hline \multirow{2}{*}{$\begin{array}{l}\text { path } \\
\text { Indirect effect }\end{array}$} & \multicolumn{4}{|c|}{ Low-cost pro-environmental behaviors } & \multicolumn{4}{|c|}{ High-cost pro-environmental behaviors } \\
\hline & Coeff & S.E. & LLCl & ULCI & Coeff & S.E. & LLCl & ULCI \\
\hline & 0.004 & 0.003 & -0.003 & 0.011 & $-0.014^{\star \star \star}$ & 0.003 & -0.020 & -0.009 \\
\hline \multirow[t]{2}{*}{ Direct effect } & Coeff & S.E. & LLCl & ULCI & Coeff & S.E. & LLCl & ULCI \\
\hline & $0.131^{\star \star \star}$ & 0.024 & 0.084 & 0.178 & -0.019 & 0.017 & -0.054 & 0.015 \\
\hline
\end{tabular}

Notes: Authors' own computation. $\mathrm{LLCl}$ and ULCI indicate the lower and upper limit of the confidence intervals; ***indicates a significant level of $1 \%$.

effect can be confidentially rejected. The results using the bootstrap method are reported in Table 6.

Table 6 shows that for low-cost pro-environmental behaviors the indirect effect is 0.004 . The $95 \%$ confidence intervals fall between -0.003 and 0.011 , suggesting that there is no mediation effect of conformity. Table 6 also shows that the direct effect of social interaction on low-cost pro-environmental behaviors is 0.131 . The corresponding confidence intervals are both positive and fall between 0.084 and 0.178 , suggesting the presence of a direct effect. Taking these results together, we find that conformity has no mediation effect for the relationship between social interaction and low-cost pro-environmental behaviors, which is consistent with the results from the stepby-step approach.

We also find that for the high-cost pro-environmental behaviors the indirect effect is -0.014 . The corresponding $95 \%$ confidence intervals fall between -0.020 and -0.009 . The direct effect of social interaction on high-cost proenvironmental behaviors is -0.019 , with the $95 \%$ confidence intervals falling between -0.054 and 0.015 . Taking these results together, we find the presence of conformity's indirect effect and the absence of social interaction's direct effect. These results are generally consistent with the results from the step-by-step approach, which confirms the robustness of our results from the mediation analysis. In other words, conformity has a full mediation effect on the relationship between social interaction and high-cost pro-environmental behaviors.

\section{DISCUSSION}

In this paper, we provide empirical evidence on whether and how social interaction may affect low-cost and high-cost proenvironmental behaviors. We find that while social interaction increases residents' low-cost pro-environmental behaviors, it decreases residents' high-cost pro-environmental behaviors. After addressing the concern of endogeneity, the heterogeneous impacts of social interaction on the two types of pro-environmental behaviors still hold, though the absolute value of the coefficients becomes larger. While some studies have analyzed the relationship between social interaction and proenvironmental behaviors (Miller and Buys, 2008; Macias and Williams, 2014), our findings contribute to the literature by highlighting the importance of distinguishing between different pro-environmental behaviors in analysis.
Several approaches may be used to distinguish proenvironmental behaviors. For example, There are civic and legal pro-environmental behaviors (Smith-Sebasto and D'Costa, 1995), active and non-active pro-environmental behaviors (Stern, 2000), private and public pro-environmental behaviors (Hunter et al., 2004), as well as low-cost and high-cost pro-environmental behaviors (Andersson and von Borgstede, 2010; Abrahamse and Steg, 2011). Enlightened by the fact that residents' pro-environmental behaviors are often cost-sensitive (Arain et al., 2020), our study follows the last approach. The analysis leads to heterogeneous impacts of social interaction on different types of pro-environmental behaviors, implying that such separation seems to be important in similar future studies.

We also find that conformity plays a mediation role in the relationship between social interaction and residents' proenvironmental behaviors. For high-cost pro-environmental behaviors, conformity has a negative mediation effect. Indeed, social interaction makes residents more familiar with social norms and residents tend to avoid deviating from the norms which may cause disutility (Akerlof and Kranton, 2000). Our findings support the above argument and further emphasize that residents not only follow the "good" norms (i.e., participating in low-cost pro-environmental behaviors), but also follow the "bad" norms (i.e., not participating in highcost pro-environmental behaviors) to pursue consistency with the social majority.

We also notice that conformity has no mediation effect on the relationship between social interaction and the low-cost proenvironmental behaviors, implying the presence of other mediators. For example, social interaction may increase the low-cost pro-environmental behaviors by allowing residents to obtain more information about the importance of environmental protection (Videras et al., 2012). Moreover, social interaction may also generate emotional bonding serving as the platform where personal resources can be mobilized and made use of ( $\mathrm{Li}$ et al., 2020b). That means individuals with strong emotional bonding may easily mobilize his or her resources to make their own contributions to the environment. Conformity has a full mediation effect for the relationship between social interaction and high-cost pro-environmental behaviors. One possible explanation is that the negative mediation effects are attached with welfare effects. Indeed, residents who spent a lot of time, effort or money on the high-cost pro-environmental behaviors before should be motivated to follow the behavioral patterns of the social majority, i.e., not participating in high-cost proenvironmental behaviors, to save the relevant cost. 


\section{CONCLUSION}

Environmental problems are rooted in various human behaviors and have been viewed as the major obstacles to sustainable development in many developing countries. The understanding of residents' motivation to participate in proenvironmental behaviors is therefore urgent. In this paper, we try to analyze residents' pro-environmental behaviors from the perspective of social interaction by distinguishing between low-cost and high-cost pro-environmental behaviors. We also investigate whether there is a mediation role of conformity for the relationship between social interaction and pro-environmental behaviors, using both the step-by-step approach and the bootstrap method.

We find that the more frequent social interaction between residents and their friends or relatives increases low-cost proenvironmental behaviors but decreases high-cost proenvironmental behaviors. While conformity has no mediation effect for the relationship between social interaction and lowcost pro-environmental behaviors, it has a full mediation role for the relationship between social interaction and high-cost pro-environmental behaviors. Overall, these findings are in line with our expectations and confirm that the impact of social interaction may vary according to what the majority of people do in the society. We conclude that residents will have a strong tendency to conform to the behavioral patterns of the social majority, especially when following the behavioral patterns of the social majority can help them to save time, effort or financial cost.

Our study may draw some important policy implications for environmental protection in China. Policy design to promote residents' pro-environmental behaviors should consider the attributes of different pro-environmental behaviors, e.g., the enforcement cost. In particular, adaptive incentive policy instruments must be developed according to the changing enforcement cost of different pro-environmental behaviors. To promote low-cost pro-environmental behaviors which are likely to have been carried out by the social majority, the creation of social norms via sharing information on environmental protection is beneficial. Thus, policy design may aim to encourage social interaction between residents or reveal the social majority's actions for environmental protection. However, for high-cost pro-environmental behaviors, social interaction could make the situation worse. Thus, to promote high-cost pro-environmental behaviors external incentives

\section{REFERENCES}

Abrahamse, W., and Steg, L. (2011). Factors Related to Household Energy Use and Intention to Reduce it: The Role of Psychological and Socio-Demographic Variables. Hum. Ecol. Rev. 18, 30-40. https://www.jstor.org/stable/24707684

Akerlof, G. A., and Kranton, R. E. (2000). Economics and Identity*. Q. J. Econ. 115, 715-753. doi:10.1162/003355300554881

Al Mamun, A., Mohamad, M. R., Yaacob, M. R. B., and Mohiuddin, M. (2018). Intention and Behavior towards green Consumption Among Low-Income Households. J. Environ. Manage. 227, 73-86. doi:10.1016/j.jenvman.2018. 08.061 should be designed to overcome enforcement cost, i.e., financial or spiritual incentives from the government to compensate residents' cost in the implementation of the behaviors could be options.

This paper may bear some limitations. First, the behavioral patterns of the social majority about pro-environmental protection could be different across years due to rapid income growth in China. Thus, readers should be cautious to generalize our results from the analysis of one-year data. Second, the nature of cross-sectional data limits our ability to control for timeinvariant factors in the regression, which raises the concern of endogeneity. Although we have employed an instrumental variable based approach to mitigate the concern, future studies should take advantage of a panel dataset to further test the robustness of our results. Third, due to data limitation, we are unable to directly test what the other mediators for the low-cost pro-environmental behaviors are, though such test in future studies would be important to understand the relationship between social interaction and pro-environmental behaviors. Fourth, our work is built on the assumption that proenvironmental behaviors are cost-sensitive, yet a direct test on such assumption in China seems to be necessary to support our research design.

\section{DATA AVAILABILITY STATEMENT}

The raw data supporting the conclusion of this article will be made available by the authors, without undue reservation.

\section{AUTHOR CONTRIBUTIONS}

YZ: Data analysis, data description, explanation of results, writing. YW: Data analysis, writing. ZL: Conceptualization, data anlaysis, methodology, explanation of results, writing, reviewing and editing.

\section{FUNDING}

This work was supported by the National Natural Science Foundation of China (grant number 17BZZ007); the Natural Science Foundation of the Higher Education Institutions of Jiangsu Province (grant number 17KJB170004).

Amoah, A., and Addoah, T. (2021). Does Environmental Knowledge Drive Proenvironmental Behaviour in Developing Countries? Evidence from Households in Ghana. Environ. Dev. Sustain. 23, 2719-2738. doi:10.1007/s10668-020-00698-x

Andersson, M., and von Borgstede, C. (2010). Differentiation of Determinants of Low-Cost and High-Cost Recycling. J. Environ. Psychol. 30, 402-408. doi:10. 1016/j.jenvp.2010.02.003

Arain, A. L., Pummill, R., Adu-Brimpong, J., Becker, S., Green, M., Ilardi, M., et al. (2020). Analysis of E-Waste Recycling Behavior Based on Survey at a Midwestern US University. Waste Manag. 105, 119-127. doi:10.1016/j. wasman.2020.02.002

Baron, R. M., and Kenny, D. A. (1986). The Moderator-Mediator Variable Distinction in Social Psychological Research: Conceptual, Strategic, and 
Statistical Considerations. J. Personal. Soc. Psychol. 51, 1173-1182. doi:10.1037/ 0022-3514.51.6.1173

Berenguer, J., Corraliza, J. A., and Martín, R. (2005). Rural-urban Differences in Environmental Concern, Attitudes, and Actions. Eur. J. Psychol. Assess. 21, 128-138. doi:10.1027/1015-5759.21.2.128

Bond, R. (2005). Group Size and Conformity. Group Process. Intergroup Relations 8, 331-354. doi:10.1177/1368430205056464

Cerin, E., Taylor, L. M., Leslie, E., and Owen, N. (2006). Small-scale Randomized Controlled Trials Need More Powerful Methods of Mediational Analysis Than the Baron-Kenny Method. J. Clin. Epidemiol. 59, 457-464. doi:10.1016/j. jclinepi.2005.11.008

DeSombre, E. R. (2018). Individual Behavior and Global Environmental Problems. Glob. Environ. Polit. 18, 5-12. doi:10.1162/glep_a_00441

Diekmann, A., and Preisendörfer, P. (2003). Green and Greenback: The behavioral effects of environmental attitudes in low-cost and high-cost situations. Rationality Soc. 15, 441-472. doi:10.1177/1043463103154002

Duarte, R., Escario, J.-J., and Sanagustín, M.-V. (2017). The Influence of the Family, the School, and the Group on the Environmental Attitudes of European Students. Environ. Edu. Res. 23, 23-42. doi:10.1080/13504622.2015.1074660

Farrow, K., Grolleau, G., and Ibanez, L. (2017). Social Norms and Proenvironmental Behavior: A Review of the Evidence. Ecol. Econ. 140, 1-13. doi:10.1016/j.ecolecon.2017.04.017

Feng, W., and Reisner, A. (2011). Factors Influencing Private and Public Environmental protection Behaviors: Results from a Survey of Residents in Shaanxi, China. J. Environ. Manage. 92, 429-436. doi:10.1016/j.jenvman.2010. 08.002

Frey, B. S., and Meier, S. (2004). Social Comparisons and Pro-social Behavior: Testing "Conditional Cooperation" in a Field Experiment. Am. Econ. Rev. 94, 1717-1722. doi:10.1257/0002828043052187

Gong, X., Zhang, J., Zhang, H., Cheng, M., Wang, F., and Yu, N. (2020). Internet Use Encourages Pro-environmental Behavior: Evidence from China. J. Clean. Prod. 256, 120725. doi:10.1016/j.jclepro.2020.120725

Hayes, A. F. (2009). Beyond Baron and Kenny: Statistical Mediation Analysis in the New Millennium. Commun. Monogr. 76, 408-420. doi:10.1080/ 03637750903310360

Huang, L., Wen, Y., and Gao, J. (2020). What Ultimately Prevents the Proenvironmental Behavior? An In-Depth and Extensive Study of the Behavioral Costs. Resour. Conservation Recycling 158, 104747. doi:10.1016/j. resconrec.2020.104747

Hunter, L. M., Hatch, A., and Johnson, A. (2004). Cross-National Gender Variation in Environmental Behaviors*. Social Sci. Q 85, 677-694. doi:10. 1111/j.0038-4941.2004.00239.x

Iosifidi, M. (2016). Environmental Awareness, Consumption, and Labor Supply: Empirical Evidence from Household Survey Data. Ecol. Econ. 129, 1-11. doi:10. 1016/j.ecolecon.2016.05.007

Kollmuss, A., and Agyeman, J. (2002). Mind the gap: Why Do People Act Environmentally and what Are the Barriers to Pro-environmental Behavior? Environ. Edu. Res. 8, 239-260. doi:10.1080/13504620220145401

Li, D., Du, J., Sun, M., and Han, D. (2020a). How Conformity Psychology and Benefits Affect Individuals' green Behaviours from the Perspective of a Complex Network. J. Clean. Prod. 248, 119215. doi:10.1016/j.jclepro.2019.119215

Li, S., Wei, M., Qu, H., and Qiu, S. (2020b). How Does Self-Image Congruity Affect Tourists' Environmentally Responsible Behavior? J. Sust. Tourism 28, 2156-2174. doi:10.1080/09669582.2020.1800717

Ling, M., and Xu, L. (2020). Relationships between Personal Values, Microcontextual Factors and Residents' Pro-environmental Behaviors: An Explorative Study. Resour. Conservation Recycling 156, 104697. doi:10.1016/ j.resconrec.2020.104697

Liu, Z., and Feng, S. (2020). Linking Political Attitude and Pro-environmental Behaviors in China. Appl. Econ. Lett. 27, 1463-1468. doi:10.1080/13504851. 2019.1690122

Liu, Z., Li, J., Rommel, J., and Feng, S. (2020a). Health Impacts of Cooking Fuel Choice in Rural China. Energ. Econ. 89, 104811. doi:10.1016/j.eneco.2020. 104811

Liu, Z., Rommel, J., Feng, S., and Hanisch, M. (2017). Can Land Transfer through Land Cooperatives foster Off-Farm Employment in China? China Econ. Rev. 45, 35-44. doi:10.1016/j.chieco.2017.06.002
Liu, Z., and Yu, L. (2020). Stay or Leave? the Role of Air Pollution in Urban Migration Choices. Ecol. Econ. 177, 106780. doi:10.1016/j.ecolecon.2020. 106780

Liu, Z., Zhang, L., Rommel, J., and Feng, S. (2020b). Do land Markets Improve Land-Use Efficiency? Evidence from Jiangsu, China. Appl. Econ. 52, 317-330. doi:10.1080/00036846.2019.1645286

Macias, T., and Williams, K. (2014). Know Your Neighbors, Save the Planet Social Capital and the Widening Wedge of Pro-Environmental Outcomes. Environ. Behav. 48, 391-420. doi:10.1177/0013916514540458

MacKinnon, D. P., Lockwood, C. M., Hoffman, J. M., West, S. G., and Sheets, V. (2002). A Comparison of Methods to Test Mediation and Other Intervening Variable Effects. Psychol. Methods 7, 83-104. doi:10.1037/1082-989x.7.1.83

Matus, K., Nam, K.-M., Selin, N. E., Lamsal, L. N., Reilly, J. M., and Paltsev, S. (2012). Health Damages from Air Pollution in China. Glob. Environ. Change 22, 55-66. doi:10.1016/j.gloenvcha.2011.08.006

Meyer, A. (2015). Does Education Increase Pro-environmental Behavior? Evidence from Europe. Ecol. Econ. 116, 108-121. doi:10.1016/j.ecolecon. 2015.04.018

Miller, E., and Buys, L. (2008). The Impact of Social Capital on Residential WaterAffecting Behaviors in a Drought-Prone Australian Community. Soc. Nat. Resour. 21, 244-257. doi:10.1080/08941920701818258

Nordlund, A., Jansson, J., and Westin, K. (2018). Acceptability of Electric Vehicle Aimed Measures: Effects of Norm Activation, Perceived justice and Effectiveness. Transportation Res. A: Pol. Pract. 117, 205-213. doi:10.1016/j. tra.2018.08.033

Nyborg, K. (2018). Social Norms and the Environment. Annu. Rev. Resour. Econ. 10, 405-423. doi:10.1146/annurev-resource-100517-023232

Ostrom, E. (2000). Collective Action and the Evolution of Social Norms. J. Econ. Perspect. 14, 137-158. doi:10.1257/jep.14.3.137

Ponce, P., Alvarado, R., Ponce, K., Alvarado, R., Granda, D., and Yaguana, K. (2019). Green Returns of Labor Income and Human Capital: Empirical Evidence of the Environmental Behavior of Households in Developing Countries. Ecol. Econ. 160, 105-113. doi:10.1016/j.ecolecon.2019.02.012

Saphores, J.-D. M., Ogunseitan, O. A., and Shapiro, A. A. (2012). Willingness to Engage in a Pro-environmental Behavior: An Analysis of E-Waste Recycling Based on a National Survey of U.S. Households. Resour. Conservation Recycling 60, 49-63. doi:10.1016/j.resconrec.2011.12.003

Schmitt, M. T., Aknin, L. B., Axsen, J., and Shwom, R. L. (2018). Unpacking the Relationships between Pro-environmental Behavior, Life Satisfaction, and Perceived Ecological Threat. Ecol. Econ. 143, 130-140. doi:10.1016/j. ecolecon.2017.07.007

Shrout, P. E., and Bolger, N. (2002). Mediation in Experimental and Nonexperimental Studies: New Procedures and Recommendations. Psychol. Methods 7, 422-445. doi:10.1037/1082-989x.7.4.422

Smith-Sebasto, N. J., and D'Costa, A. (1995). Designing a Likert-type Scale to Predict Environmentally Responsible Behavior in Undergraduate Students: A Multistep Process. J. Environ. Edu. 27, 14-20. doi:10.1080/00958964.1995. 9941967

Stern, P. C. (2000). New Environmental Theories: Toward a Coherent Theory of Environmentally Significant Behavior. J. Soc. Isssues 56, 407-424. doi:10.1111/ 0022-4537.00175

van Riper, C., Winkler-Schor, S., Foelske, L., Keller, R., Braito, M., Raymond, C., et al. (2019). Integrating Multi-Level Values and Pro-environmental Behavior in a U.S. Protected Area. Sustain. Sci. 14, 1395-1408. doi:10.1007/s11625-01900677-w

Vesely, S., Klöckner, C. A., and Brick, C. (2020). Pro-environmental Behavior as a Signal of Cooperativeness: Evidence from a Social Dilemma experiment. J. Environ. Psychol. 67, 101362. doi:10.1016/j.jenvp.2019.101362

Videras, J., Owen, A. L., Conover, E., and Wu, S. (2012). The Influence of Social Relationships on Pro-environment Behaviors. J. Environ. Econ. Manag. 63, 35-50. doi:10.1016/j.jeem.2011.07.006

Wang, E., and Kang, N. (2018). Does Life Satisfaction Matter for Proenvironmental Behavior? Empirical Evidence from China General Social Survey. Qual. Quant. 53, 449-469. doi:10.1007/s11135-018-0763-0

Wang, E. S.-T., and Lin, H.-C. (2017). Sustainable Development: The Effects of Social Normative Beliefs on Environmental Behaviour. Sust. Dev. 25, 595-609. doi:10.1002/sd.1680 
Wang, P., Liu, Q., and Qi, Y. (2014). Factors Influencing Sustainable Consumption Behaviors: a Survey of the Rural Residents in China. J. Clean. Prod. 63, 152-165. doi:10.1016/j.jclepro.2013.05.007

Welsch, H., Binder, M., and Blankenberg, A.-K. (2021). Green Behavior, green SelfImage, and Subjective Well-Being: Separating Affective and Cognitive Relationships. Ecol. Econ. 179, 106854. doi:10.1016/j.ecolecon.2020.106854

Xiao, C., Dunlap, R. E., and Hong, D. (2013). The Nature and Bases of Environmental Concern Among Chinese Citizens. Soc. Sci. Q. 94, 672-690. doi:10.1111/j.1540-6237.2012.00934.x

Xiao, S., Dong, H., Geng, Y., and Brander, M. (2018). An Overview of China's Recyclable Waste Recycling and Recommendations for Integrated Solutions. Resour. Conservation Recycling 134, 112-120. doi:10.1016/j.resconrec.2018. 02.032

Xiao, S., Dong, H., Geng, Y., Tian, X., Liu, C., and Li, H. (2020). Policy Impacts on Municipal Solid Waste Management in Shanghai: A System Dynamics Model Analysis. J. Clean. Prod. 262, 121366. doi:10.1016/j.jclepro.2020. 121366

Xu, L., Ling, M., Lu, Y., and Shen, M. (2017). External Influences on Forming Residents' Waste Separation Behaviour: Evidence from Households in Hangzhou, China. Habitat Int. 63, 21-33. doi:10.1016/j.habitatint.2017.03.009
Zhang, P., Zou, Z., Liu, G., Feng, C., Liang, S., and Xu, M. (2020). Socioeconomic Drivers of Water Use in China during 2002-2017. Resour. Conservation Recycling 154, 104636. doi:10.1016/j.resconrec.2019.104636

Zibenberg, A., Greenspan, I., Katz-Gerro, T., and Handy, F. (2018). Environmental Behavior Among Russian Youth: The Role of SelfDirection and Environmental Concern. Environ. Manage. 62, 295-304. doi:10.1007/s00267-018-1032-7

Zivin, J. G., and Neidell, M. (2012). The Impact of Pollution on Worker Productivity. Am. Econ. Rev. 102, 3652-3673. doi:10.1257/aer.102.7.3652

Conflict of Interest: The authors declare that the research was conducted in the absence of any commercial or financial relationships that could be construed as a potential conflict of interest.

Copyright (c) $2021 \mathrm{Zhu}$, Wang and Liu. This is an open-access article distributed under the terms of the Creative Commons Attribution License (CC BY). The use, distribution or reproduction in other forums is permitted, provided the original author(s) and the copyright owner(s) are credited and that the original publication in this journal is cited, in accordance with accepted academic practice. No use, distribution or reproduction is permitted which does not comply with these terms. 


\section{APPENDIX ACCORDING TO BARON AND KENNY (1986), CASUAL STEPS APPROACH REFERS TO THE FOLLOWING DIAGRAM:}

The coefficient $\alpha_{1}$ is the total effect of social interaction on proenvironmental behaviours; the coefficient $\beta_{1}$ is the effect of social interaction on conformity; the coefficient $\gamma_{1}$ is the effect of conformity on pro-environmental behaviours after controlling for the effect of social interaction; the coefficient $\gamma_{2}$ is the direct effect of social interaction on proenvironmental behaviours after controlling for the effect of conformity.
The mediation effect is equal to the indirect effect, i.e., the multiplication of the coefficients $\beta_{1}{ }^{*} \gamma_{1}$, which has the following relationship with the total effect and the direct effect:

$$
\alpha_{1}=\gamma_{2}+\beta_{1} * \gamma_{1}
$$

The casual steps approach has three main steps: The first step is to test the significance of the total effect, i.e., the impact of social interaction on pro-environmental behaviours; The second step is to test the significance of the multiplication of coefficients (with null hypothesis: $\beta_{1}{ }^{*} \gamma_{1}=0$ ) indirectly by sequentially testing coefficients $\beta_{1}$ and $\gamma_{1}$; Thee third test is to distinguish between full and partial mediation. If $\gamma_{2}$ is significant and less than $\alpha_{1}$, it is partially mediated; if $\gamma_{2}$ is not significant, it is fully mediated. 